\title{
LIFTING MECHANISM FOR ATTACHMENTS OF AGRICULTURAL EQUIPMENTS
}

\author{
Neil Purandare $^{1}$, Ashish Shejwal ${ }^{2}$, Hrishikesh Sane ${ }^{3}$, Siddharth Patil ${ }^{4}$ \\ ${ }^{I}$ B.E, Mechanical, M.I.T., Maharastra, India \\ ${ }^{2}$ B.E, Mechanical, M.I.T., Maharastra, India \\ ${ }^{3}$ B.E, Mechanical, M.I.T., Maharastra, India \\ ${ }^{4}$ B.E, Mechanical, M.I.T., Maharastra, India
}

\begin{abstract}
In the field of agriculture numerous equipments are used for various purposes. These attachments like plough, harrow, chisel plough, cultipacker, etc are mounted on the operating machine through an attachment which is then lifted as per requirement with the help of a hydraulic mechanism. No matter how efficient a mechanism might be, cost has always been and will be an important factor to decide which lifting mechanism to opt for. Hydraulic mechanism being costly, this newly designed mechanism is one of the cheapest amongst all others in the market. The main objective of the design has been coping for the high cost and bulky nature of hydraulic mechanisms to meet the attachment lifting requirements of the hand operated light weight machinery. Relative sliding motion of wedges is used for lifting of load. The wedges are actuated by a power screw. Our mechanism is designed by keeping in mind the light weight attachments like plough, supreme, ultimus, etc of a power tiller. Though it can be used in agricultural machines involving lifting of various attachments with necessary changes in dimensions of our prescribed design. The same mechanism can be used for lifting action of other heavy weight attachments of heavy duty machines. One of the primary objective of the design has been to substantially reduce the cost and size of the existing mechanism. Box dimension of our design is comparatively much less than other designs available in the market. This reduction in cost makes the mechanism affordable for farmers of every class. For commercialization other electronic actuating mechanisms can be used with the basic design structure remaining the same. It was observed that of all components bell crank is the most critical component, which was successfully analyzed for the required load.
\end{abstract}

Keywords: bell crank, holder, wedges, base, actuating mechanism, plough, C40, lowering action, lifting action

\section{DESIGNED MECHANISM}

Our newly designed mechanism has the advantage of being compact with very less box dimension. Comparatively with three point hitch mechanism, it is much less in size and weight. It can be utilized for heavy weight as well as light weight hand operated machinery. Movement of the wedges is used to facilitate the movement of the attachment. High strength material like $\mathrm{C} 40$ is used to provide the necessary strength [5].

\subsection{Experimental Setup}

Our set up consist of 1 plough with, 1 holder, 1 bell crank, 2 wedges( 1 upper wedge, 1 lower wedge), 1 base, 1 actuating mechanism(here, power screw). When the power screw rotates in one side (clockwise), it will push the lower wedge to front. Due to its movement, the upper wedge will lift upwards. The upper wedge will push the bell crank on front side and it will lower the plow. This action is known as Lowering Action. Similarly, when the power screw rotates in one side (anti-clockwise), it will pull the lower wedge on back side. Due to its movement, the upper wedge will go downwards. The upper wedge will pull the bell crank on back side and it will lift the plow. This action is known as Lifting Action. $* * *$

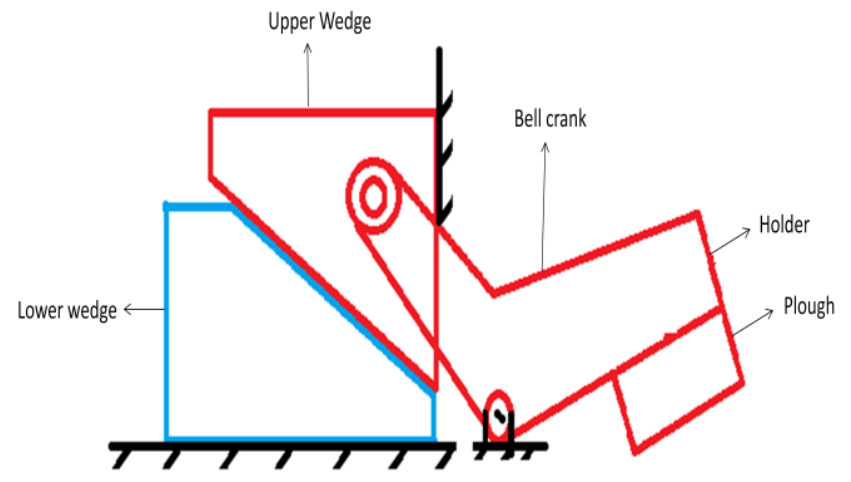

Fig-1: Block diagram of experimental setup

\section{MAIN PARTS}

For every component we have selected FOS 4.We have selected C40 Material for all components. [2]

\subsection{Holder}

Holder is the main component of mechanism which attached with plough. Its main function is to lift the plough in required angle. As name suggests it hold plough and so all the weight of plough will act on holder. For calculating the 
bending moment acting on holder due to weight of plough formula given below is used

Bending Moment $=$ wt of plough $(\mathrm{W})^{*}$ length $(\mathrm{L})[1]$

\subsection{Bell Crank}

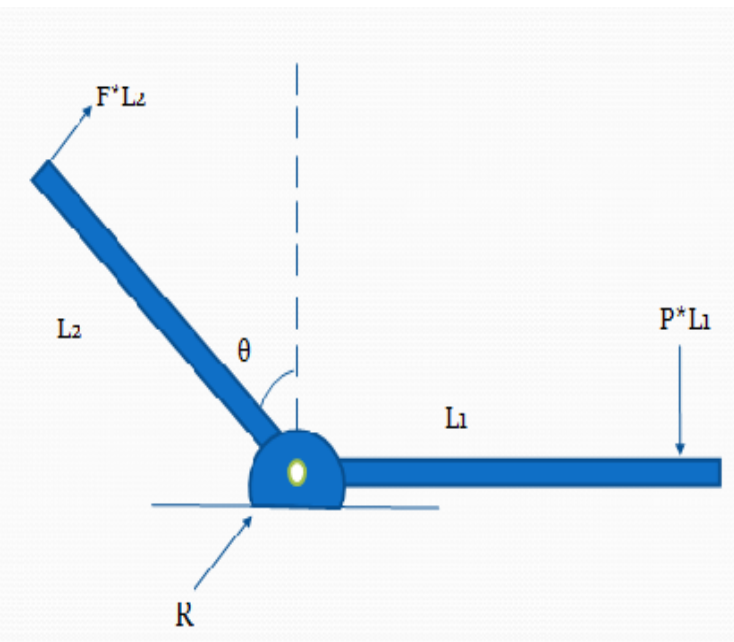

Fig-2: FBD of bell crank.

$$
\begin{gathered}
\mathrm{F}^{*} \mathrm{~L}_{2}=\mathrm{P}^{*} \mathrm{~L}_{1} \\
\mathrm{R}=\sqrt[2]{\left(\mathrm{F}^{\wedge} 2+\mathrm{P}^{\wedge} 2-2 \mathrm{FPCOS} \alpha\right)}[1][4]
\end{gathered}
$$

Where,

$\mathrm{F}=$ Effort required

$\mathrm{P}=$ Force produced by liver

L2=Distance between centers of wedge pin and fulcrum pin

L1 = Distance between centers of holder bolt and fulcrum pin

$\mathrm{R}=$ Reaction at fulcrum pin

$\alpha=$ Angle between two links $=90^{\circ}+\alpha$.

Cross section of bell crank can be designed by calculating bending moment acting on it and according to cross-section selected like Rectangle, I-section, elliptical section. Forces and design of bush bearing and fulcrum pin can be obtained from reaction acting on bell crank.[1]

\subsection{Wedges}

Angle of wedge $=15^{0}$

Density of material $=7.86 * 10^{-4} \mathrm{~kg} / \mathrm{mm}^{3}$

$\mathrm{P}=$ output force on wedge 2

$\mathrm{N} 1=$ normal force between wedge and bell crank

$\mathrm{N} 2=$ normal force between wedge 1 and wedge 2

$\mathrm{N} 3=$ normal force between wedge 2 and base

$\mu=$ coefficient of friction between surface $=0.3$

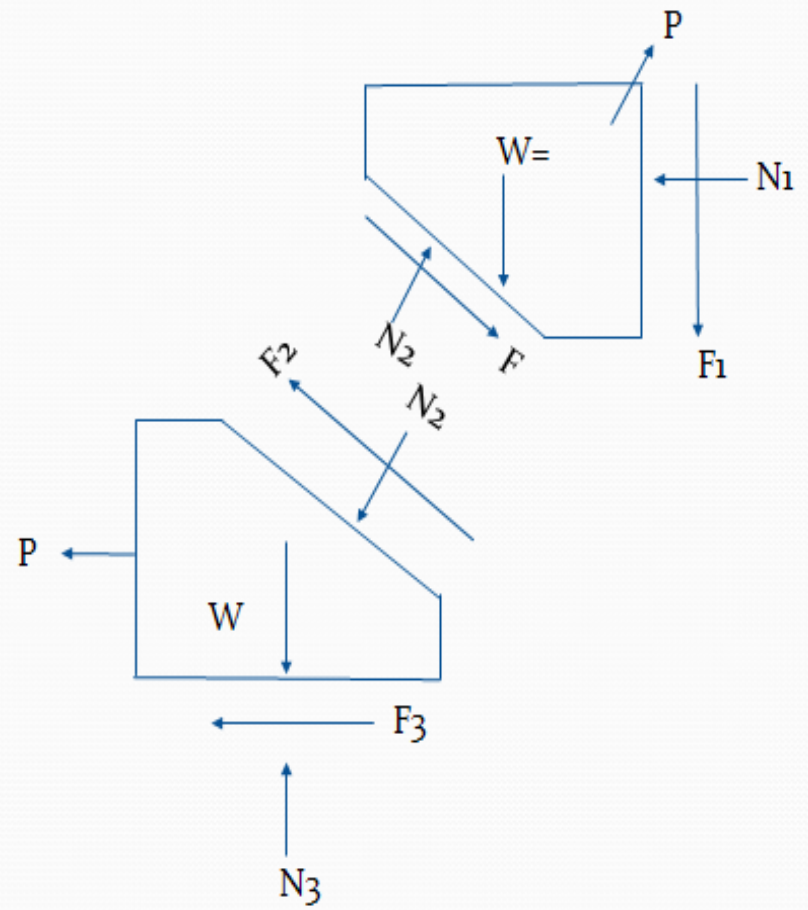

Fig-3: Forces acting on wedges.

F1: $\mu * \mathrm{~N} 1$ (Frictional force) [5]

F2: $\mu * \mathrm{~N} 2$ (Frictional force) [5]

F3: $\mu * \mathrm{~N} 3$ (Frictional force) [5]

$\mathrm{P}$ : Input force

$\mathrm{W}$ : Weight of wedge

$\mathrm{N} 1, \mathrm{~N} 2, \mathrm{~N} 3$ - Normal reactions

Overall length, height, width can be decided as per space available and volume to be required. [5]

\subsection{Base}

Base plates support the entire mechanism and to carry the slots of the wedges. Hence their dimensions are decided according to the dimensions of the wedges and the bell crank. Base plate is attached to restrict the backward motion of the lower wedge so that it does not slip out from its slot and to support the power screw which is actuating mechanism.

\subsection{Actuating Mechanism}

As we have used comparatively lower weight for lifting, we have selected hand operated power screw for operating purpose due to its self-locking property. However, for use in tractors the hand operated power screws can be replaced with a high power motor if the weight of plough is higher.[5][4]

\section{FINAL DIAGRAMS OF COMPONENTS}

The final diagrams are created using CAD software like PRO-E and Unigraphics. The dimensions of each and every component are based on calculations. Where required necessary data is assumed for calculations purpose 


\subsection{Holder}
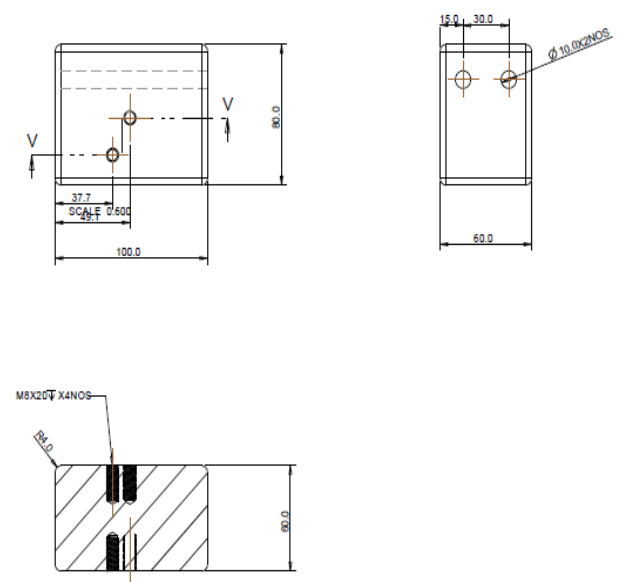

HOLDER

Fig-4: 3 views of holder.

\subsection{Bell Crank}

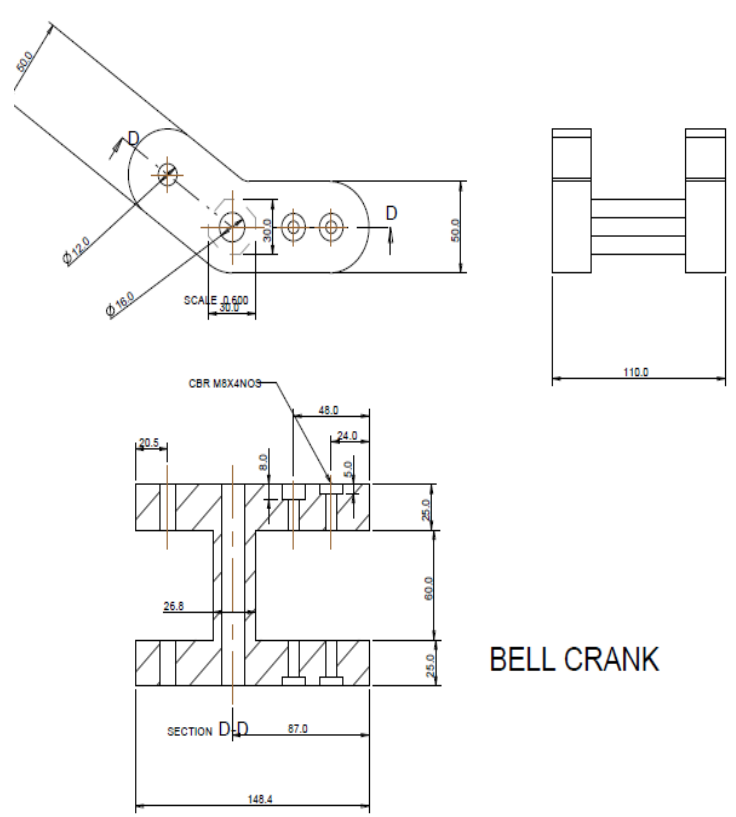

Fig-5: 3 views of bell crank.

\subsection{Wedges}

\subsubsection{Wedge 1}

Wedge 1 or upper wedge has T-slot to slide in wedge 2 or lower wedge. The motion obtained from wedge 2 is transferred to wedge 1 and then to bell crank.

\subsubsection{Wedge 2}

Wedge 2 has two extension of $80 \mathrm{X} 10 \mathrm{X} 10$ (all in $\mathrm{mm}$ ) to slide on base and to keep contact with surface of base while sliding. The extension plays role of a guide way to wedge 2 .
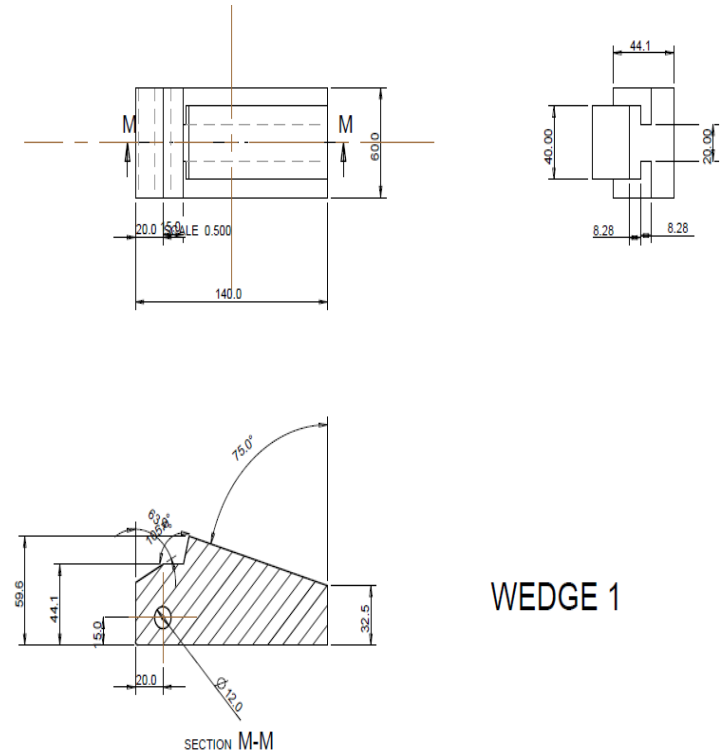

WEDGE 1

Fig-6: 3 views of wedge 1 .
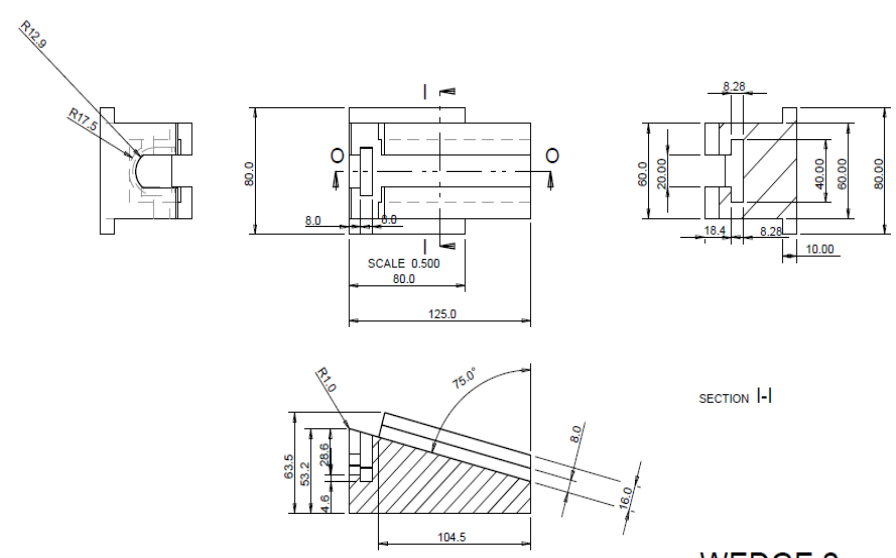

SECTION I-I

WEDGE 2

\subsection{Base}

\subsubsection{Base Plate 1}
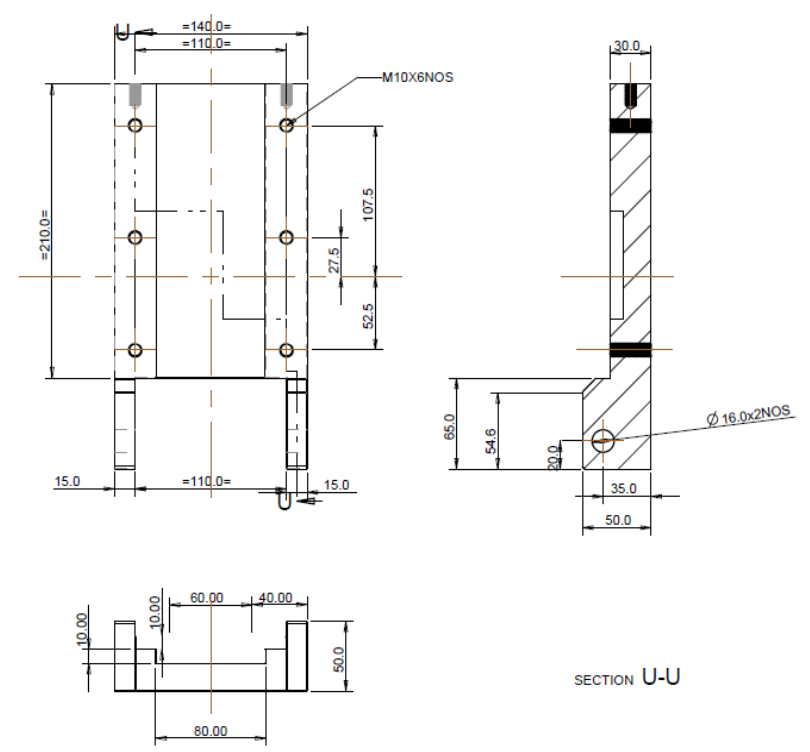

SECTION U-U

Fig-8: 3 views of base plate 1 . 


\subsubsection{Base Plate 2}

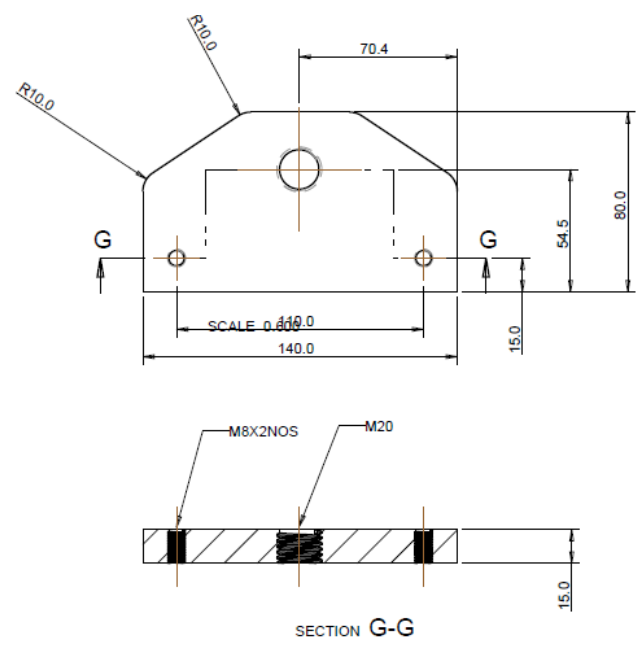

Fig-9: 2 views of base plate 2 .

\section{ANALYSIS OF CRITICAL PART (BELL CRANK)}

In the designed mechanism it is observed that bell crank is the most critical part. The system is based on design of failure of the two pins. Hence bell crank is a component which is going to carry the primary loads.

\subsection{Input for Analysis}

Objective: To find out deflection and stresses in bell crank. Input: Bell crank CAD Model.

Tool used: MESHING: - HYPERMESH 11.0

SOLVER: - RADIOSS 11.0.

Table-1: material input for analysis.

\begin{tabular}{|c|c|c|c|c|c|c|}
\hline \multirow[b]{2}{*}{$\begin{array}{l}\mathbf{S} \\
\mathbf{R} . \\
\mathbf{N} \\
\mathbf{O}\end{array}$} & \multirow[b]{2}{*}{$\begin{array}{l}\text { PART } \\
\text { NAME }\end{array}$} & \multirow[b]{2}{*}{$\begin{array}{l}\text { MATER } \\
\text { IAL } \\
\text { NAME }\end{array}$} & \multicolumn{3}{|c|}{$\begin{array}{l}\text { MECHANICAL } \\
\text { PROPERTIES }\end{array}$} & \multirow[b]{2}{*}{$\begin{array}{l}\text { Yield } \\
\text { streng } \\
\text { th } \\
(\mathrm{MPa}) \\
\end{array}$} \\
\hline & & & \begin{tabular}{|l} 
YOUNG \\
S \\
MODUL \\
US \\
(MPa) \\
\end{tabular} & $\begin{array}{l}\text { POISSO } \\
\text { NS } \\
\text { RATIO }\end{array}$ & $\begin{array}{l}\text { DENSI } \\
\text { TY } \\
(\mathrm{g} / \mathrm{cc})\end{array}$ & \\
\hline 1 & $\begin{array}{l}\text { BELL } \\
\text { CRAN } \\
\mathrm{K}\end{array}$ & $\mathrm{C} 40$ & 210000 & 0.3 & 7.9 & 390 \\
\hline
\end{tabular}

\subsection{Plough Loading}

Plough loading includes $100 \mathrm{~kg}$ plough wt and $4.5 \mathrm{~kg}$ holder weight as shown in mesh below.

$\square$ All DOF constrained

$\mathrm{X}$ rotation free, rest DOF Fixed

Plough load

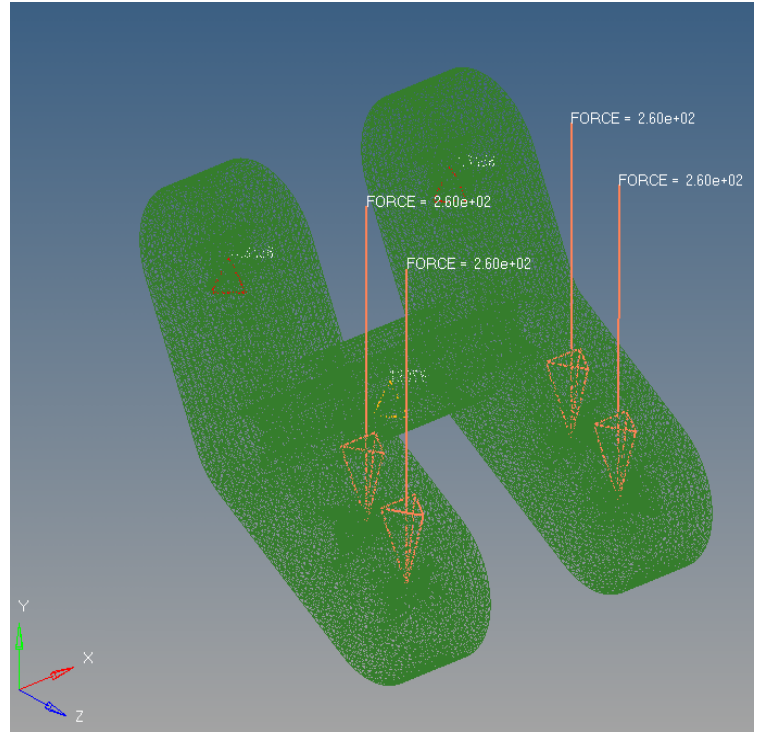

Fig-10: Plough loading and constraints.

\subsection{Deflection Plot}

- $\quad$ For Load: $104.5 \mathrm{~kg}$

Maximum Deflection: $0.00194 \mathrm{~mm}$
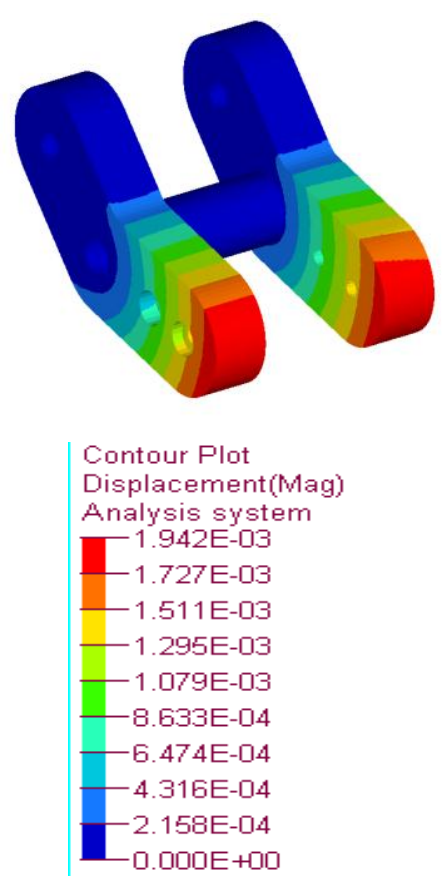

Fig-10: Deflection Plot (Load $104.5 \mathrm{~kg})$.

- $\quad$ For Load: $304.5 \mathrm{~kg}$

Maximum Deflection: $0.00567 \mathrm{~mm}$ 


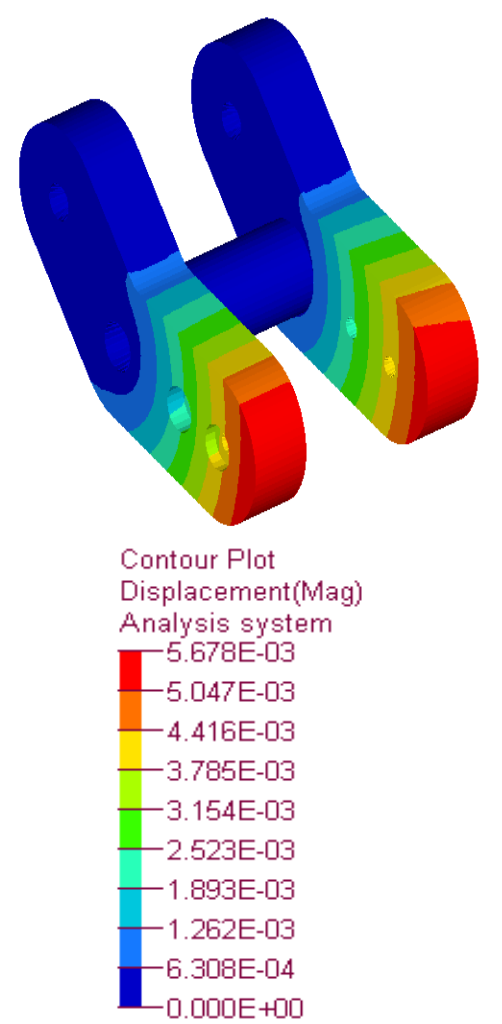

Fig-11: Deflection Plot (Load $304.5 \mathrm{~kg})$

\subsection{Stress Plot}

- $\quad$ For Load: $104.5 \mathrm{~kg}$

Maximum Deflection: $0.00194 \mathrm{~mm}$
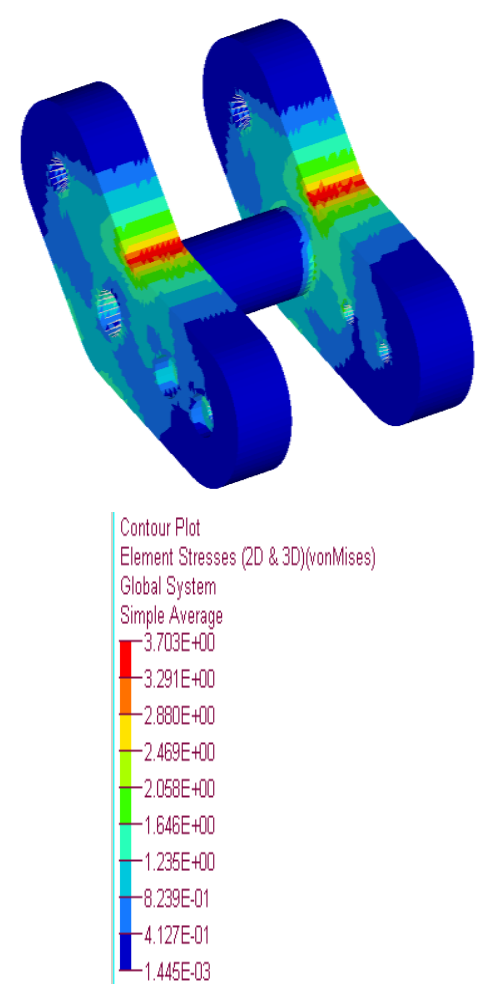

Fig-12: Stress Plot (Load $104.5 \mathrm{~kg})$.
- $\quad$ For Load: $304.5 \mathrm{~kg}$

Maximum Deflection: $0.00567 \mathrm{~mm}$
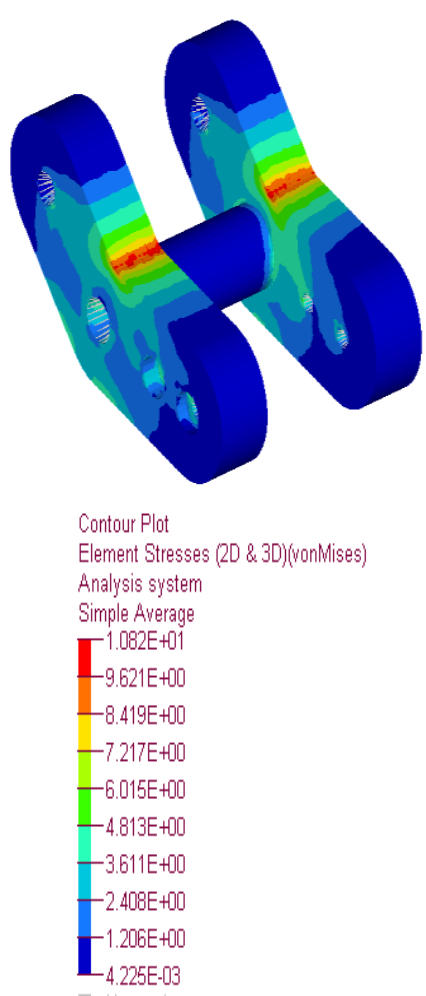

Fig-13: Stress Plot (Load $304.5 \mathrm{~kg})$.

\subsection{Analysis Result}

\begin{tabular}{|c|c|c|c|c|}
\hline $\begin{array}{l}\text { SUB } \\
\text { CASES }\end{array}$ & $\begin{array}{l}\text { Paramete } \\
\text { rs }\end{array}$ & $\begin{array}{l}\text { FOR } \\
\text { LOAD :- } \\
104.5 \mathrm{lgg}\end{array}$ & $\begin{array}{l}\text { FOR } \\
\text { LOAD :- } \\
304.5 \mathrm{lgg}\end{array}$ & Remarks \\
\hline \multirow{2}{*}{$\begin{array}{l}\text { Plough } \\
\text { loading }\end{array}$} & $\begin{array}{l}\text { Deflection } \\
(\mathrm{mm})\end{array}$ & 0.00194 & $0.005^{6} 7$ & $\begin{array}{c}\text { Within } \\
\text { material } \\
\text { yield limit. }\end{array}$ \\
\hline & $\begin{array}{l}\text { Stress } \\
\text { (Mpa) }\end{array}$ & 3.7 & 10.8 & $\begin{array}{c}\text { Within } \\
\text { material } \\
\text { yield limit. }\end{array}$ \\
\hline
\end{tabular}

\section{CAD MODELS}

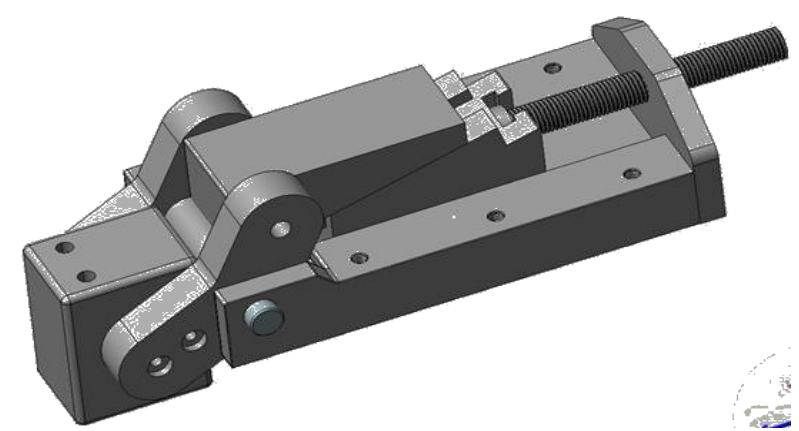

Fig-14: Isometric view of mechanism (one side). 


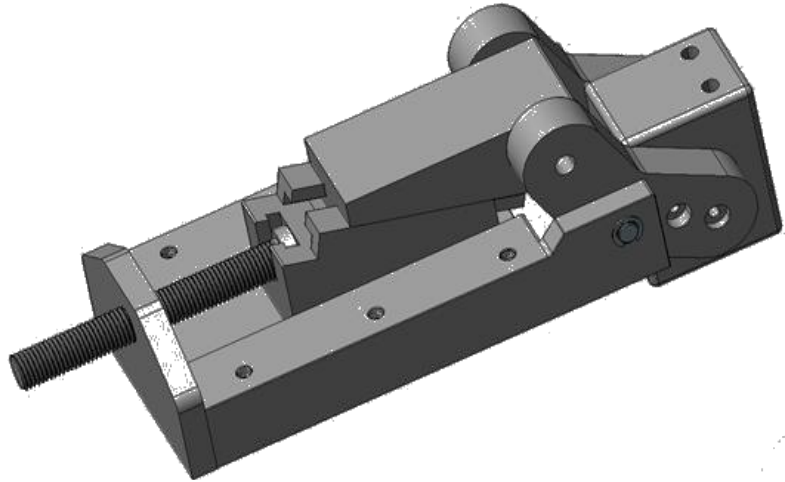

Fig-15: Isometric view of mechanism (other side).

\section{RESULTS}

The prototype which is made of aluminium weights $8.2 \mathrm{~kg}$ was tested with a virtual plough ( $\mathrm{L}$ shaped rod) and a $\mathrm{C}$ shape section. The total weight of the attachment was observed to be $10 \mathrm{~kg}$. The rod of length $1000 \mathrm{~mm}$ and height $300 \mathrm{~mm}$. At the topmost position the distance from the ground and the tip of the L section is $500 \mathrm{~mm}$. The upward angular displacement of the bell crank is $20^{\circ}$ from the horizontal and the lower angular displacement is $5^{\circ}$. The tooth of the plough can go $125 \mathrm{~mm}$ deep in the ground.

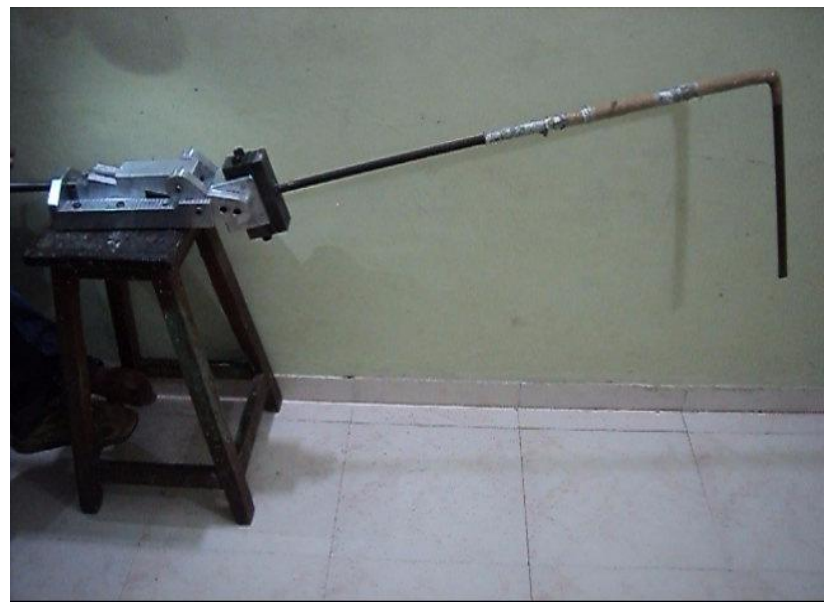

Fig-16: L-shaped rod in lifted position.

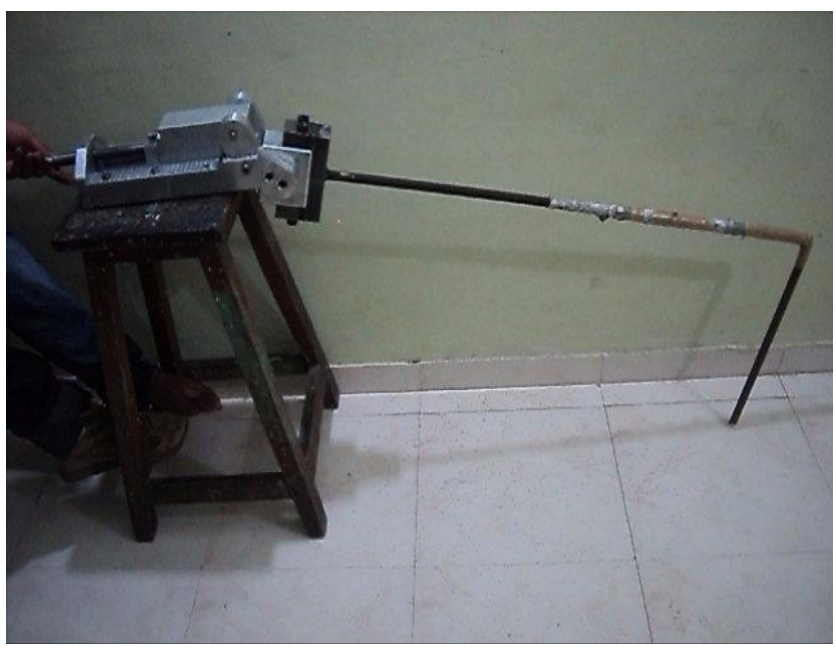

Fig-16: L-shaped rod in downward position.

\section{CONCLUSIONS}

The output motion of the prototype is as required. Load is easily sustained by the mechanism. Power required to lift the plough is higher than what was earlier determined. A more efficient and commercial mechanism can be derived from the existing mechanism eliminating the few drawbacks. Attachments of wide range of applications can be used. The bell crank is designed for load of $100 \mathrm{~kg}$ and as per the analysis it can sustain $304.5 \mathrm{~kg}$ of load with the maximum displacement of $0.00567 \mathrm{~mm}$ and maximum stress of $10.8 \mathrm{MPa}$. The assembled mechanism is working as expected.

\section{FUTURE SCOPE}

Modification for other purposes:

- $\quad$ For use in tractors the hand operated power screws can be replaced with a high power motor if the mechanism is to be operated using a switch.

- Designed mechanism can be used as general purpose lifting mechanism with required modifications in wide range of application.

- Material and size of mechanism can be varied for heavy load application other than agriculture.

- It can be used in industries for lifting of heavy loads where motion along an arc is to be achieved.

- $\quad$ High cost efficiency makes it suitable for other uses.

\section{REFERENCES}

[1] Design of machine elements - V.B. Bhandari

[2] PSG Design Data Book

[3] Westermann Table

[4] Applied Strength of Materials, $4^{\text {th }}$ edition -Robert L. Mott

[5] Wikipedia

\section{BIOGRAPHIES}

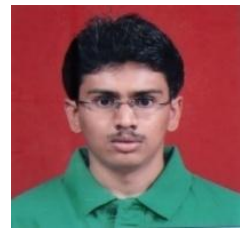

Neil Purandare, born in Maharashtra, India in 1993. He secured his degree in B.E. Mechanical from Maharashtra Institute of Technology, pune, in 2014. He has completed his project and worked as Intern at varroc polymers pvt. Ltd. He has interest in Future studies and his research interested fields are Design field, Product Design and Development and PLM.

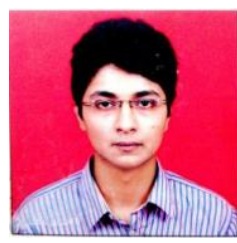

Ashish shejwal, born in Maharashtra, India in 1993. He secured his degree in B.E. Mechanical from Maharashtra Institute of Technology, pune, in 2014. He has completed his project and worked as Intern at varroc polymers pvt. Ltd. And interned in mahindra and mahindraand volkswagon. Future studies and interest in Design field and metallurgy. 


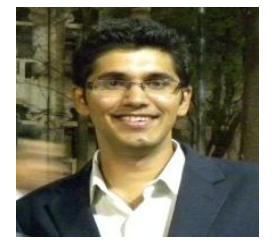

Hrishikesh Sane, born in Maharashtra, India in 1992. He secured his degree in B.E. Mechanical from Maharashtra Institute of Technology, pune, in 2014. Future studies and interest in Design field.

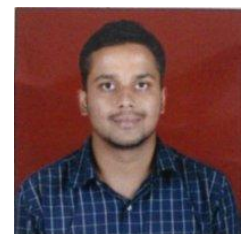

Siddharth Patil, born in Maharashtra, India in 1992. He secured his degree in B.E. Mechanical from Maharashtra Institute of Technology, pune , in 2014. Future studies and interest in Design field and process industry. 